\title{
Biological correlates of sea urchin recruitment in kelp forest and urchin barren habitats
}

\author{
B. Weitzman ${ }^{1,2,3, *}$, B. Konar ${ }^{2}$ \\ ${ }^{1}$ US Geological Survey, Alaska Science Center, Anchorage, AK 99508, USA \\ ${ }^{2}$ University of Alaska Fairbanks, College of Fisheries and Ocean Sciences, Fairbanks, AK 99709, USA \\ ${ }^{3}$ Present address: NOAA, National Ocean Service, National Centers for Coastal Ocean Science, Homer, AK 99603, USA
}

\begin{abstract}
Shifts between the alternate stable states of sea urchin barren grounds and kelp forests correspond to sea urchin density. In the Aleutian Archipelago, green sea urchins Strongylocentrotus polyacanthus are the dominant herbivores that graze kelp forests. Sea urchin recruitment is an important driver that influences sea urchin density, particularly in the absence of topdown control from a keystone predator such as the sea otter Enhydra lutris. To understand how the biological community may influence patterns of sea urchin recruitment, we compared sea urchin recruit (size $\leq 20 \mathrm{~mm}$ ) densities with biomass of other benthic organisms in both barren ground and kelp forest habitats at 9 islands across the Aleutian Archipelago. Patterns of biological community structure between the 2 habitats did not explain patterns of sea urchin recruits; however, the same 10 specific taxa were found to correlate with sea urchin recruits in each habitat. Taxa that showed strong positive correlations included Codium, Constantinea, Schizymenia, and hydrozoans, while strong negative correlations were observed with Pachyarthron and Pugettia. Weak positive correlations were observed with Alcyonidium and ascidiaceans in both habitats, while weak variable relationships were detected with Polysiphonia and Corallina between habitats. The observed species-specific relationships may be due to small sea urchin displacement by larger conspecifics, larval responses to settlement cues, post-settlement survival via biogenic refugia, or potentially predation. These potential species-specific interactions were apparent, regardless of habitat, and it can be inferred that they would be preserved in the presence or absence of keystone predation.
\end{abstract}

KEY WORDS: Kelp forest · Nearshore habitats $\cdot$ Recruitment $\cdot$ Species interaction $\cdot$ Urchin barrens

\section{INTRODUCTION}

Sea urchins are often the key herbivore causing the transition between the alternate stable states of kelp forest (high fleshy macroalgal cover and low urchin density) to barren ground (low fleshy macroalgal cover and high urchin density) habitats on temperate rocky reefs (Estes \& Duggins 1995, Gagnon et al. 2004, Filbee-Dexter \& Scheibling 2014). Habitat shifts towards sea urchin barrens have been reported across temperate latitudes globally (Johnson et al. 2011, Ling et al. 2015, Krumhansl et al. 2016). Sea

*Corresponding author: ben.weitzman@noaa.gov urchins can have important effects on marine habitats, as they heavily graze fleshy macroalgae and cause bioerosion of biogenic reef habitats (Steneck et al. 2017, Rasher et al. 2020). They also provide a key food source for upper trophic levels, such as the sea otter Enhydra lutris in the north Pacific (Watt et al. 2000, Larson et al. 2015). Urchin demographics influence the role that urchins play in an ecosystem as a herbivore or as prey. Demographic factors such as size, fecundity, and recruitment will affect population density, grazing rates, and movement (Himmelman 1986, Dumont et al. 2006). While effects that

(C) The authors 2021. Open Access under Creative Commons by Attribution Licence. Use, distribution and reproduction are unrestricted. Authors and original publication must be credited. 
urchins can have on habitat and ecosystem structure and the role that they play in food webs are well known, the drivers of sea urchin demographics are complex. Sea urchin demographics may be influenced by environmental gradients (Ebert 2010, Ling et al. 2015) and can vary greatly across regions due to environmental forcing on sea urchins through ontogeny (Estes \& Duggins 1995). Recruitment and post-settlement survival is a fundamental process in sea urchin demographics.

Biological drivers can have a strong influence on sea urchin recruitment through multiple pathways that influence post-settlement distribution, growth, and survival. Sea urchin growth and age structure can be influenced by the algal cover on which they are feeding (Ling et al. 2019). Additionally, the whipping action of kelps, particularly Desmarestia viridis and Eualaria fistulosa, can physically prevent sea urchins from overgrazing (Konar et al. 2014). Globally, top-down control of sea urchin demographics via predation has long been recognized (Pederson \& Johnson 2006, Fagerli et al. 2014, Sheppard-Brennand et al. 2017). In the Aleutian Archipelago of Alaska, the precipitous decline of sea otters in the late 1990s and early 2000s, likely due to killer whale predation (Estes et al. 1998), has allowed us to examine how benthic ecosystems function in the absence of keystone predators. Here, the presence of both barren ground and kelp forest habitats across the Aleutian Archipelago offers an ideal opportunity to investigate how biological features influence sea urchin recruitment within these 2 habitats. Kelp forests are believed to be more biodiverse and productive than barren grounds, with a large amount of food available to sea urchins that can survive. The obvious differences in community structure between kelp forest and barren ground habitats are likely to drive differences in sea urchin recruitment, which may differ between kelp forest and barren grounds (Himmelman 1986) due to differences in pre- and post-settlement processes that regulate growth and survival of newly recruited sea urchins (Rowley 1989).

Here, we ask how the surrounding biological community influences patterns of sea urchin recruitment and whether taxa that are correlated with recruits differ between kelp forest and barren ground habitats. We hypothesized that given the different community structures between barren grounds (low fleshy macroalgal cover and high urchin density) and kelp forests (high fleshy macroalgal cover and low urchin density), there would likely be different biological correlates of sea urchin recruitment. However, if there were similar species associated with sea urchin recruitment in both habitats, this would suggest overarching species interactions that are key drivers to sea urchin recruitment, regardless of habitat state.

\section{MATERIALS AND METHODS}

At 9 islands in the Aleutian Archipelago, from Chuginadak in the east to Attu in the west (Fig. 1), a total of 360 benthic community quadrats were examined from both habitats, barren ground or kelp forest, in August 2016 and 2017. At each island, 4 sites were established, 2 within each habitat type that best represented these habitats based on the presence or absence of consistently dense subcanopy kelps across the entire area to be sampled (see Metzger et al. 2019 for details on community structure within both types of habitats). While some limited fleshy macroalgae were found in barrens, there was an obvious lack of kelp species (primarily Eualaria, Thalassiophyllum, and Saccharina) and an abundance of sea urchins. All sites were in approximately 6 to $8 \mathrm{~m}$ water depth, on rocky benches along exposed shorelines. At each site, divers using SCUBA scraped all mobile and sessile epibiota from each of 10 haphazardly placed $0.25 \mathrm{~m}^{2}$ quadrats into a fine mesh pillow case. All invertebrates and macroalgae were returned to the shipboard laboratory for species identification and quantification of total wet biomass (g). All organisms were visually identified to the finest taxonomic resolution possible with the aid of light micro-

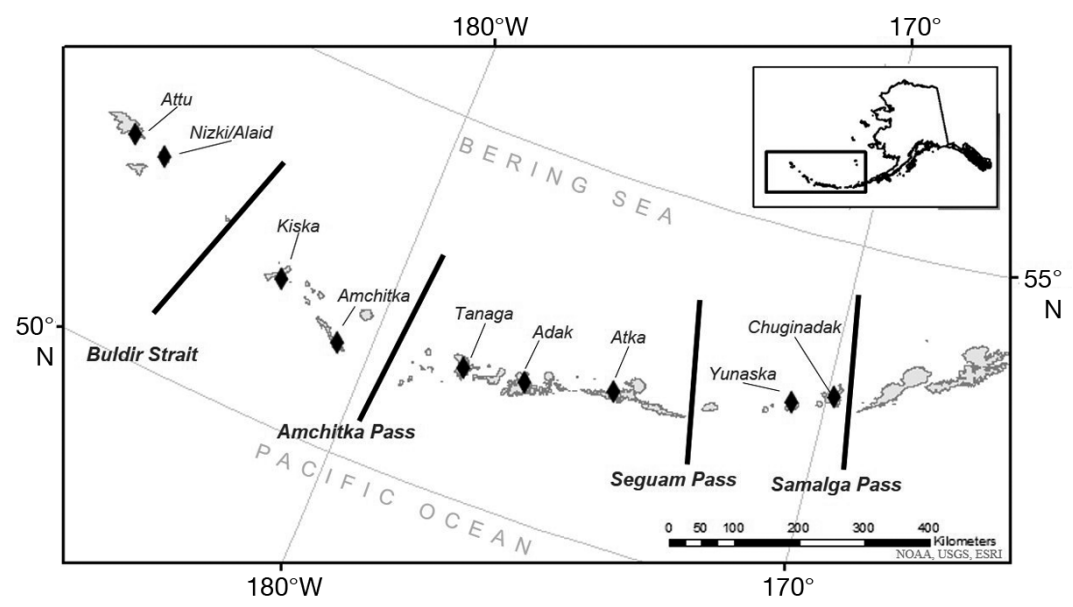

Fig. 1. The Aleutian Archipelago with study islands. ( ) Benthic community sampling sites 
scopes and species keys. Test diameters of all sea urchins were measured to the nearest $\mathrm{mm}$ using calipers to determine size frequencies within each quadrat.

Data used in this study were initially analyzed for overall community structure differences between habitats (Metzger et al. 2019) and then archived with the Biological \& Chemical Oceanography Data Management Office as epibenthic community abundance (Edwards \& Konar 2018a) and biomass (Edwards \& Konar 2018b). Our analyses used PRIMER v7 and PERMANOVA+ (PRIMER-e, Quest Research; Anderson et al. 2008, Clarke et al. 2014, Clarke \& Gorley 2015). Individual sea urchin sizes were assigned a size class (Recruit: $\leq 20 \mathrm{~mm}$, Small: $21-35 \mathrm{~mm}$, Medium: 36-54 mm, or Large: $\geq 55 \mathrm{~mm}$; Estes \& Duggins 1995, Brady \& Scheibling 2006, Scheibling \& Hatcher 2013) and standardized to a proportional scale (from 0.0 to 1.0) among all samples for analyses. Each size bin was treated as an ordered variable and a BrayCurtis (with 0.01 dummy variable added) similarity matrix was constructed to compare similarity in size distributions between habitats and among islands. Recruits were then selected and used to construct another Bray-Curtis (with 0.1 dummy variable added) similarity matrix of recruit densities by quadrat to test for similarities in the densities of recruits among samples. From the same quadrats, biomass of the surrounding biological community (fleshy and upright coralline macroalgae and invertebrates) was fourthroot transformed, to down-weight dominant taxa and allow for consideration of the full biological community. The biomass data were then constructed into a Bray-Curtis (with 0.01 dummy variable added) similarity matrix to test for similarities in the biomass of the surrounding biological community. Samples were the quadrat level data $(\mathrm{n}=180$ per habitat) from each of ten $0.25 \mathrm{~m}^{2}$ quadrats per site. The permutational multivariate analysis of variance (PERMANOVA) design was Habitat (Kelp, Barrens), Islands (Attu, Semichis [Nizki/Alaid], Kiska, Amchitka, Tanaga, Adak, Atka, Yunaska, and Chuginadak), Habitat $\times$ Islands, Site(Island), Quadrat(Site). Quadrat data were ordinated by non-metric multidimensional scaling (nMDS) to visualize similarity in sea urchin recruitment among all quadrats across all islands, by habitat. Bubble plots were imposed on points in nMDS space to depict relative differences in sea urchin recruit densities and vector plots show the correlated community taxa driving separation among points in nMDS space. Differences between habitats for both the recruit densities and the surrounding community were separately tested by a 2-way crossed permutational ANOVA
(PERMANOVA $;$ McArdle \& Anderson 2001) with Habitat treated as a fixed factor and Island treated as a random factor. A similarity percentage analysis (SIMPER) was used to determine the community taxa most important in explaining the dissimilarity in community structure between habitats. A distance based linear regression (DistLM; Anderson et al. 2008) analysis was used to statistically determine the community taxa that were significantly correlated with sea urchin recruit densities, using the fourth-root transformed community biomass by quadrat as the predictor variable worksheet. DistLM and nMDS were constructed for barren ground and remnant kelp forest habitats independently, to determine taxa that were significantly correlated with sea urchin recruits in both habitats.

\section{RESULTS}

Patterns of sea urchin size frequency distributions were variable between habitats and among islands (Fig. 2). Standardized sea urchin size frequencies did not significantly differ between habitats $(\mathrm{p}($ perm $)=$ 0.06 , pseudo- $F=2.4$ ); however, the interaction between habitat and island was significant $(\mathrm{p}($ perm $)=$ 0.001 , pseudo- $F=8.0$ ) suggesting that random effects, by island, influenced the differences in size distributions among islands. Generally, and as expected, sea urchins occurred at higher densities in the barren ground habitat than in the kelp forest habitat. Sea urchins also varied in density among islands. Islands with the highest densities (Kiska, Amchitka, and Tanaga) featured a mode over recruit sea urchin sizes, while those with moderate densities (Adak, Atka, Yunaska, and Chuginadak) featured a primary mode over the small and medium sea urchin sizes. Attu and the Semichi Islands had the lowest sea urchin densities, and the mode was focused on large sea urchins, which were uncommon at most other islands. Densities of large and small sea urchins were significantly different among islands and in quadrats with higher large urchin densities, sea urchin recruit densities were significantly lower $(p($ perm $)<0.05$; Fig. 3). While some islands had significantly higher sea urchin recruit densities, sea urchin recruits were observed in both habitats at all islands.

Community structure as measured by biomass differed significantly between barren ground and kelp forest habitats $(\mathrm{p}(\mathrm{perm})=0.003$, pseudo- $F=11.5)$ at all islands $(\mathrm{p}(\mathrm{perm})<0.001)$, despite a significant interaction term between habitat and island $(\mathrm{p}($ perm $)=$ 0.001 , pseudo- $F=9.4$ ). In total, 170 identified taxa 

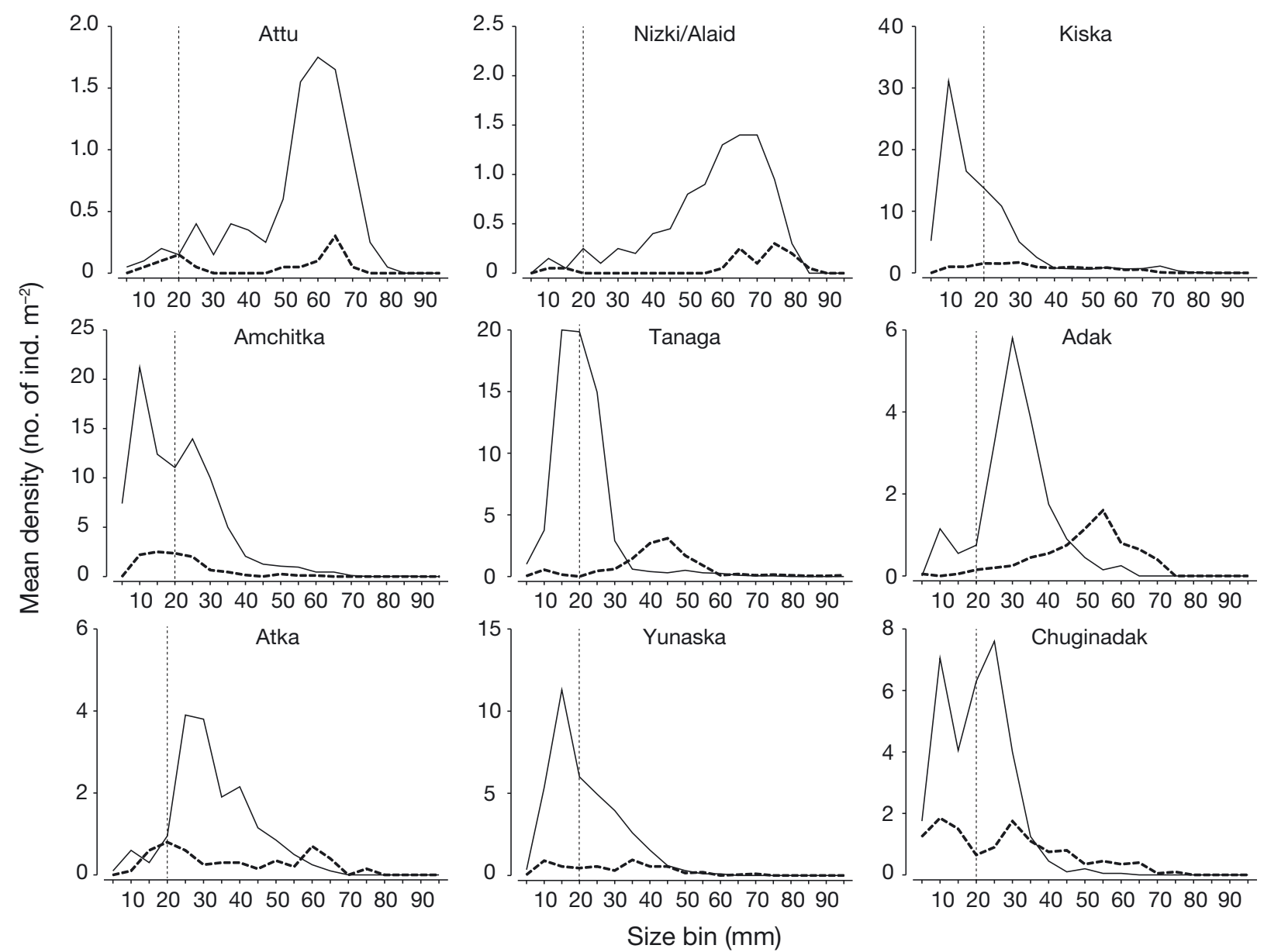

Fig. 2. Mean size distributions showing summed densities of measured sea urchins in $5 \mathrm{~mm}$ size-bins, averaged between sites $(\mathrm{n}=2)$, by habitat: barren (solid line) and kelp (dashed line) for each island. The vertical dashed line at $20 \mathrm{~mm}$ marks the cutoff for the recruit size class. Note different $y$-axis scales reflecting differences in abundance among islands (range $=<1-40$ )

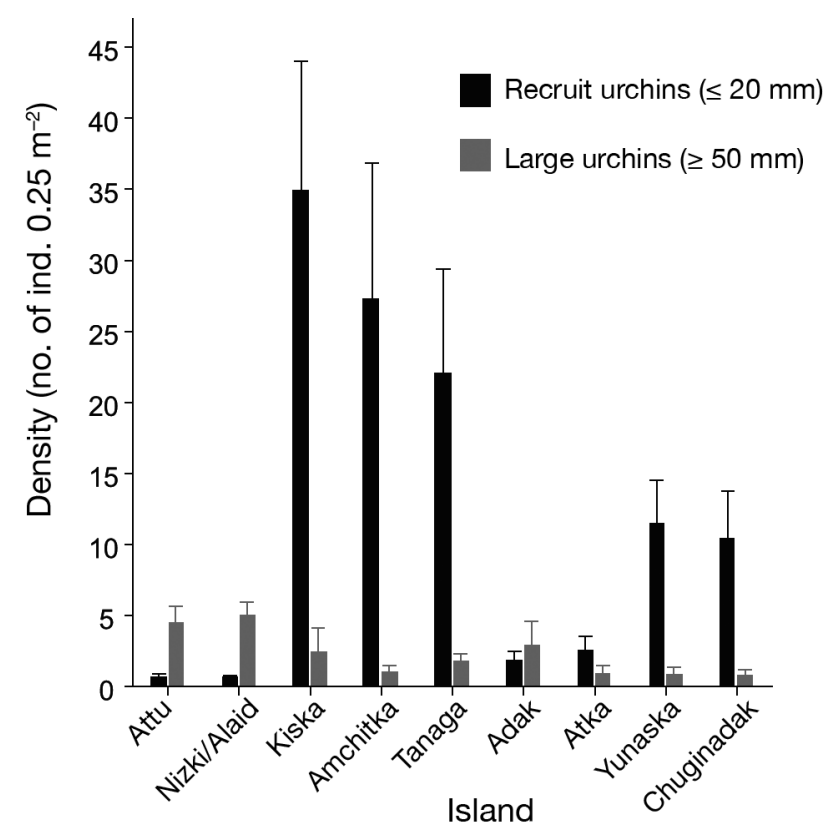

were observed in the benthic biomass scrapes, 116 were observed in barren ground and 148 were observed in kelp forest habitats. Among all taxa, 27 explained $70 \%$ of the observed dissimilarity between barren ground and kelp forest habitats (Table 1). Taxa that contributed at least $5 \%$, individually, to dissimilarity between habitats were the kelps Thalassiophyllum (7.15\%), Eualaria (6.34\%), and Saccharina $(4.66 \%)$, and sea urchins Strongylocentrotus $(4.62 \%)$. Most taxa driving the dissimilarity between habitats occurred in greater biomass in kelp forests, except for Strongylocentrotus, the green alga Codium, the upright coralline alga Pachyarthron, the rock jingle Pododesmus, and the limpet Lottia, which occurred in greater biomass in barren grounds (Table 1).

Fig. 3. Mean density (no. of ind. $0.25 \mathrm{~m}^{-2}$ ) of recruit and large sea urchin size classes averaged among sites by island ( $\mathrm{n}=4,2$ of each habitat). Error bars show $\mathrm{SD}$ 
Table 1. Results from SIMPER analysis for dissimilarity of fourth-root transformed community biomass between barren ground and kelp forest habitats. Average fourth root biomass of each taxa and the calculated dissimilarities (average dissimilarity and dissimilarity/SD) show differences between habitats. Untransformed biomass values are shown for reference. The percent variation explaining the dissimilarity for each taxon is provided individually and cumulatively, up to a cut-off of $75 \%$ cumulative variation explained

\begin{tabular}{|c|c|c|c|c|c|c|c|c|}
\hline \multirow[t]{2}{*}{ Taxa } & \multicolumn{2}{|c|}{ Jrchin barren average biomass } & \multicolumn{2}{|c|}{ Kelp forest average biomass } & \multirow{2}{*}{$\begin{array}{l}\text { Avg. } \\
\text { diss. }\end{array}$} & \multirow{2}{*}{$\begin{array}{c}\text { Diss./ } \\
\text { SD }\end{array}$} & \multirow{2}{*}{$\underset{\%}{\text { Indiv. }}$} & \multirow{2}{*}{$\begin{array}{c}\text { Cumul. } \\
\%\end{array}$} \\
\hline & 4 th root $(\sqrt[4]{g})$ & Untrans. (g) & 4 th root $(\sqrt[4]{g})$ & Untrans. (g) & & & & \\
\hline Thalassiophyllum & 0.01 & $1.00 \times 10^{-8}$ & 0.81 & $4.30 \times 10^{-1}$ & 6.00 & 1.16 & 7.15 & 7.15 \\
\hline Eualaria & 0.01 & $1.00 \times 10^{-8}$ & 0.70 & $2.40 \times 10^{-1}$ & 5.31 & 0.94 & 6.34 & 13.49 \\
\hline Saccharina & 0.00 & $0.00 \times 10^{0}$ & 0.53 & $7.89 \times 10^{-2}$ & 3.91 & 0.74 & 4.66 & 18.16 \\
\hline Strongylocentrotus & 0.91 & $6.86 \times 10^{-1}$ & 0.76 & $3.34 \times 10^{-1}$ & 3.88 & 1.10 & 4.62 & 22.78 \\
\hline Odonthalia & 0.01 & $1.00 \times 10^{-8}$ & 0.47 & $4.88 \times 10^{-2}$ & 3.63 & 1.10 & 4.32 & 27.10 \\
\hline Acarnus & 0.08 & $4.10 \times 10^{-5}$ & 0.44 & $3.75 \times 10^{-2}$ & 3.25 & 1.18 & 3.88 & 30.98 \\
\hline Ptilota & 0.01 & $1.00 \times 10^{-8}$ & 0.36 & $1.68 \times 10^{-2}$ & 2.71 & 0.79 & 3.23 & 34.21 \\
\hline Halichondria & 0.03 & $8.10 \times 10^{-7}$ & 0.36 & $1.68 \times 10^{-2}$ & 2.63 & 0.79 & 3.13 & 37.34 \\
\hline Desmarestia & 0.04 & $2.56 \times 10^{-6}$ & 0.29 & $7.07 \times 10^{-3}$ & 2.31 & 0.71 & 2.75 & 40.09 \\
\hline Codium & 0.19 & $1.30 \times 10^{-3}$ & 0.18 & $1.05 \times 10^{-3}$ & 2.25 & 0.75 & 2.68 & 42.76 \\
\hline Laminaria & 0.00 & $0.00 \times 10^{0}$ & 0.27 & $5.31 \times 10^{-3}$ & 1.98 & 0.54 & 2.37 & 45.13 \\
\hline Ascidiacea & 0.10 & $1.00 \times 10^{-4}$ & 0.25 & $3.91 \times 10^{-3}$ & 1.97 & 0.91 & 2.35 & 47.48 \\
\hline Hydrozoa & 0.16 & $6.55 \times 10^{-4}$ & 0.22 & $2.34 \times 10^{-3}$ & 1.86 & 0.99 & 2.22 & 49.70 \\
\hline Styela & 0.02 & $1.60 \times 10^{-7}$ & 0.25 & $3.91 \times 10^{-3}$ & 1.80 & 0.81 & 2.15 & 51.85 \\
\hline Constantinea & 0.14 & $3.84 \times 10^{-4}$ & 0.18 & $1.05 \times 10^{-3}$ & 1.78 & 0.84 & 2.12 & 53.97 \\
\hline Leptasterias & 0.05 & $6.25 \times 10^{-6}$ & 0.21 & $1.94 \times 10^{-3}$ & 1.64 & 0.86 & 1.96 & 55.93 \\
\hline Agarum & 0.00 & $0.00 \times 10^{0}$ & 0.18 & $1.05 \times 10^{-3}$ & 1.56 & 0.38 & 1.86 & 57.78 \\
\hline Pugettia & 0.05 & $6.25 \times 10^{-6}$ & 0.18 & $1.05 \times 10^{-3}$ & 1.46 & 0.81 & 1.74 & 59.52 \\
\hline Tonicella & 0.08 & $4.10 \times 10^{-5}$ & 0.11 & $1.46 \times 10^{-4}$ & 1.21 & 0.71 & 1.44 & 60.97 \\
\hline Pachyarthron & 0.11 & $1.46 \times 10^{-4}$ & 0.07 & $2.40 \times 10^{-5}$ & 1.18 & 0.65 & 1.41 & 62.37 \\
\hline Musculus & 0.02 & $1.60 \times 10^{-7}$ & 0.14 & $3.84 \times 10^{-4}$ & 1.10 & 0.69 & 1.31 & 63.68 \\
\hline Alcyonidium & 0.02 & $1.60 \times 10^{-7}$ & 0.15 & $5.06 \times 10^{-4}$ & 1.06 & 0.46 & 1.26 & 64.94 \\
\hline Pododesmus & 0.09 & $6.56 \times 10^{-5}$ & 0.06 & $1.30 \times 10^{-5}$ & 1.02 & 0.44 & 1.21 & 66.15 \\
\hline Lottia & 0.12 & $2.07 \times 10^{-4}$ & 0.04 & $2.56 \times 10^{-6}$ & 1.00 & 0.67 & 1.20 & 67.35 \\
\hline Turnerella & 0.06 & $1.30 \times 10^{-5}$ & 0.09 & $6.56 \times 10^{-5}$ & 1.00 & 0.55 & 1.19 & 68.54 \\
\hline Polysiphonia & 0.04 & $2.56 \times 10^{-6}$ & 0.10 & $1.00 \times 10^{-4}$ & 0.99 & 0.45 & 1.18 & 69.73 \\
\hline Henricia & 0.01 & $1.00 \times 10^{-8}$ & 0.12 & $2.07 \times 10^{-4}$ & 0.91 & 0.57 & 1.08 & 70.81 \\
\hline Schizymenia & 0.09 & $6.56 \times 10^{-5}$ & 0.05 & $6.25 \times 10^{-6}$ & 0.90 & 0.58 & 1.08 & 71.96 \\
\hline Porifera & 0.03 & $8.10 \times 10^{-7}$ & 0.10 & $1.00 \times 10^{-4}$ & 0.86 & 0.54 & 1.03 & 72.98 \\
\hline Mikamiella & 0.02 & $1.60 \times 10^{-7}$ & 0.10 & $1.00 \times 10^{-4}$ & 0.83 & 0.53 & 0.99 & 73.97 \\
\hline Dermaturus & 0.04 & $2.56 \times 10^{-6}$ & 0.09 & $6.56 \times 10^{-5}$ & 0.78 & 0.60 & 0.93 & 74.90 \\
\hline
\end{tabular}

Patterns of similarity in sea urchin recruit occurrence among all quadrats were correlated with specific invertebrate and macroalgal taxa in both barren ground and kelp forest habitats (Fig. 4). While overall benthic community structure differed between habitats and sea urchin recruits were correlated with slightly different taxa between habitats, 10 taxa were significantly correlated in both habitats $(p<0.05$, Table 2). Of the 10 significantly correlated taxa, the geniculate coralline alga Pachyarthron and the crab Pugettia showed strong negative correlations with sea urchin recruits, while the green alga Codium, the fleshy red algae Constantinea and Schizymenia, and hydroids exhibited strong positive correlations (Fig. 4). While significantly correlated in both habitats, the Alcyonidium bryozoan, the Ascidiacea tunicates, the filamentous red alga Polysiphonia, and geniculate coralline alga Corallina all showed weaker correla- tions with sea urchin recruits than the aforementioned taxa. Alcyonidium and Ascidiacea generally showed positive correlations with sea urchin recruits. Polysiphonia and Corallina exhibited mixed correlations with sea urchin recruits, dependent on habitat; where correlations with Polysiphonia were negative and Corallina somewhat neutral in barren grounds, while in kelp forests, correlations with Corallina were negative and Polysiphonia slightly positive (Fig. 4).

\section{DISCUSSION}

Variability of sea urchin demography can be influenced by patterns of recruitment over space and time. Our results suggest that specific taxa can play an important role in shaping patterns of sea urchin recruitment through potentially positive or negative 


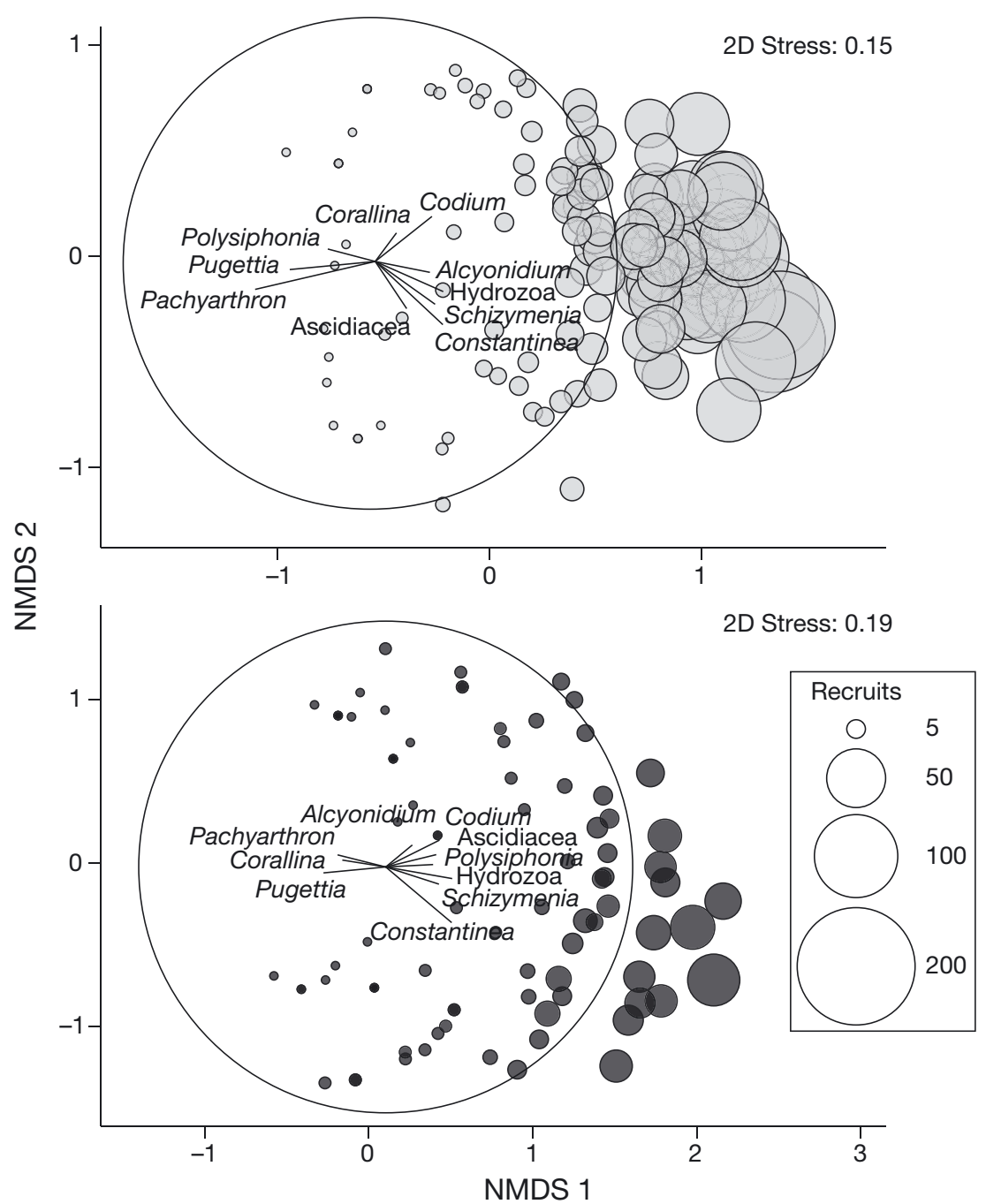

Fig. 4. nMDS plot of similarity of sea urchin recruit similarities (zero-corrected Bray-Curtis) by quadrat for barren ground (top) and kelp forest (bottom) habitats. Bubble plot shows densities (no. of ind. $0.25 \mathrm{~m}^{-2}$ ) of sea urchin recruits (test diameter $\leq 20 \mathrm{~mm}$ ). Vectors show the strength of correlations with taxa significantly correlated in both habitats by DistLM (Table 2) and the circle represents a unit of 1.0 correlation strength

interactions with sea urchin recruits that are likely more pronounced in the absence of the keystone predator in the system, sea otters. By examining correlations between other benthic taxa and sea urchin recruits at the quadrat level in 2 alternate stable state habitats, barren grounds and kelp forests, our findings pinpoint which taxa are key biological correlates with sea urchin recruitment. We rejected our initial hypothesis that the taxa driving patterns of sea urchin recruits would differ between barren ground and kelp forest habitats, because although some of the correlated taxa differed, the taxa most strongly correlated with sea urchin recruits were similar in both habitats, suggesting species-specific interactions that are not habitat-specific. Also, despite differences in sea urchin abundance between habitats, it was puzzling that patterns of standardized sea urchin size distributions did not significantly differ between habitats; however, this pattern varied among islands such that there was a strong interaction between habitat and island (as seen in Fig. 2 for 6 of the 9 islands) and suggests that local processes likely shaped patterns of growth and survival among samples.

Densities of sea urchin recruits were different between habitats and among islands; however, where they occurred, sea urchin recruits were positively associated with the encrusting green alga Codium, the red algae Constantinea and Schizymenia, and hydrozoan invertebrates. In contrast, sea urchin recruits were negatively associated with the geniculate coralline alga Pachyarthron and the decorator crab Pugettia. Sea urchin recruit densities also were inversely correlated with large sea urchins (Fig. 3). This study has pinpointed correlations between specific community taxa and sea urchin recruits, which may be indicative of a causative relationship.

\subsection{Correlations with macroalgae}

The encrusting green alga Codium occurred in dense patches in both kelp forests and barren grounds. Despite the potential for being overgrazed, Codium is one of the few macroalgae that persists and thrives in barren grounds (Metzger et al. 2019). The association between sea urchin recruits and Codium could be due to several possible relationships. Codium could be a food source for sea urchins, as they have been documented to consume it; however, Codium is not a very nutritious resource for sea urchins (Trowbridge 1995, Suskiewicz \& Johnson 2017). Perhaps sea urchin recruits are instead feeding on the biofilm that occurs on the surface of the Codium and not relying on the alga for nutrition (Zhang et al. 2014). Codium can also produce dimethylsulfoniopropionate (DMSP, Lyons et al. 2010) as a chemical defense strategy; however, DMSP can also act as a chemical attractant to sea 
Table 2. DistLM results for community biomass of taxa that were determined to be significantly correlated $(p<0.05)$ with sea urchin recruits in both barren ground and kelp forest habitats, out of the full community ( $\mathrm{n}=170$ taxa). The proportion of explained variation (Prop. exp. var.) shows the contribution of each taxa to the amount of explainable observed variation for each habitat, independently

\begin{tabular}{|c|c|c|c|c|c|c|}
\hline \multirow[t]{2}{*}{ Taxa } & \multicolumn{3}{|c|}{ Kelp forest } & \multicolumn{3}{|c|}{ _ Barren ground } \\
\hline & pseudo- $F$ & $\mathrm{p}$ & $\begin{array}{l}\text { Prop. } \\
\text { exp. var. }\end{array}$ & pseudo- $F$ & $\mathrm{p}$ & $\begin{array}{c}\text { Prop. } \\
\text { exp. var. }\end{array}$ \\
\hline Alcyonidium & 4.038 & 0.008 & $2.22 \%$ & 4.338 & 0.003 & $2.38 \%$ \\
\hline Ascidiacea & 6.915 & 0.001 & $3.74 \%$ & 2.816 & 0.017 & $1.56 \%$ \\
\hline Codium & 3.031 & 0.020 & $1.67 \%$ & 4.516 & 0.001 & $2.47 \%$ \\
\hline Constantinea & 7.569 & 0.001 & $4.08 \%$ & 3.870 & 0.006 & $2.13 \%$ \\
\hline Corallina & 3.469 & 0.011 & $1.91 \%$ & 3.098 & 0.009 & $1.71 \%$ \\
\hline Hydrozoa & 6.960 & 0.001 & $3.76 \%$ & 5.153 & 0.001 & $2.81 \%$ \\
\hline Pachyarthron & 2.965 & 0.022 & $1.64 \%$ & 17.818 & 0.001 & $9.10 \%$ \\
\hline Polysiphonia & 3.160 & 0.014 & $1.74 \%$ & 2.641 & 0.016 & $1.46 \%$ \\
\hline Pugettia & 3.673 & 0.012 & $2.02 \%$ & 9.075 & 0.001 & $4.85 \%$ \\
\hline Schizymenia & 4.702 & 0.001 & $2.57 \%$ & 4.907 & 0.002 & $2.68 \%$ \\
\hline
\end{tabular}
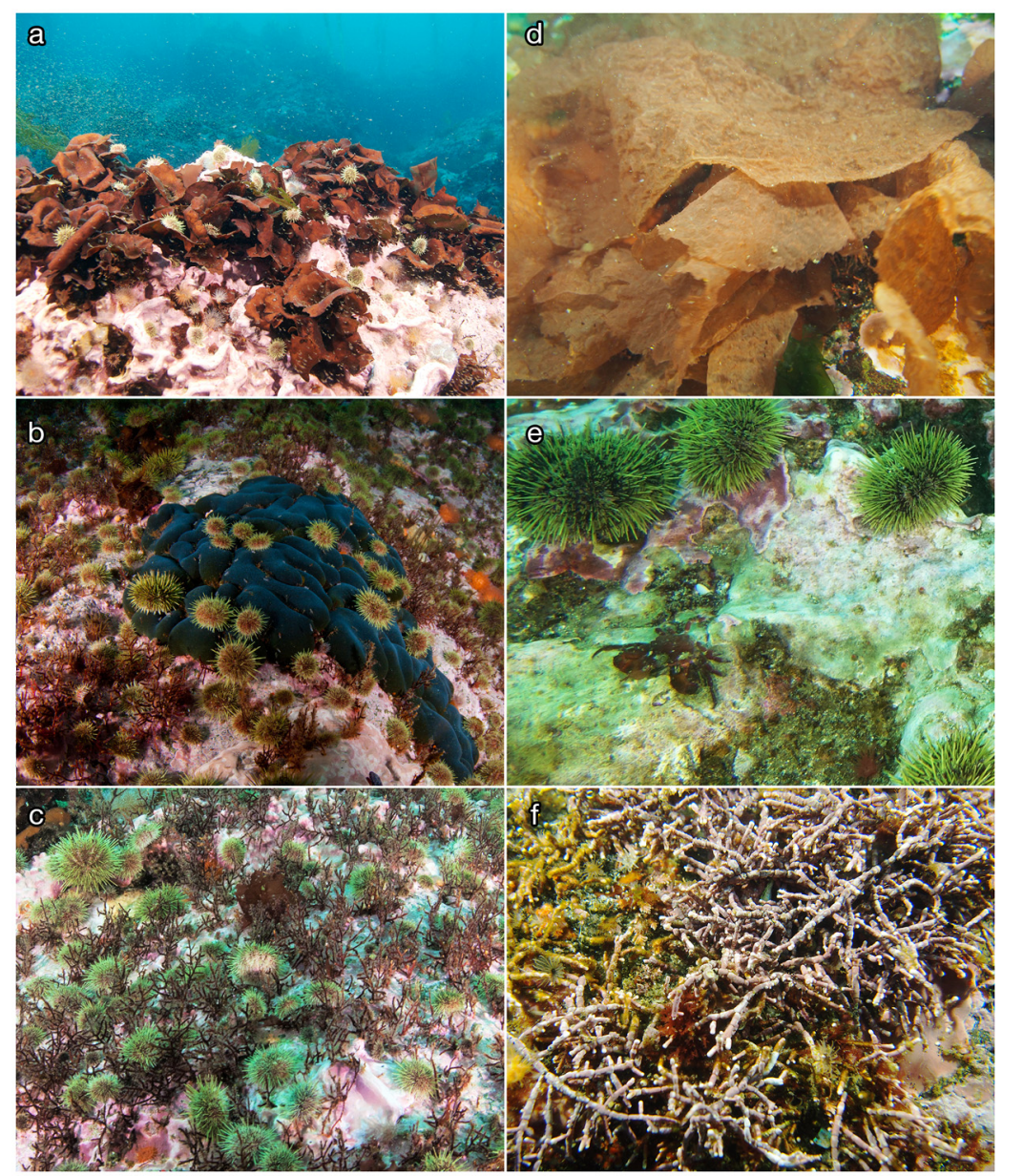

Fig. 5. Some community taxa that were significantly correlated with sea urchin recruits ( $\leq 20 \mathrm{~mm}$ ): (a) Constantinea, (b) Codium, (c) Hydrozoa, (d) Schizymenia, (e) Pugettia and large Strongylocentrotus, and (f) Pachyarthron. Photo credits: (a) Shawn Harper (www.seaweedsofalaska.com/species.asp? SeaweedID=218), (b,c) Joseph Tomoleoni (USGS-Western Ecological Research Center), (d,f) B. Konar, and (e) Melissa Good (Sea Grant Alaska) urchins (Van Alstyne et al. 2001, Van Alstyne \& Puglisi 2007). It is unknown if the chemical compounds within Codium act as an attractant or deterrent to sea urchins. It is likely that sea urchin recruits are using the folds and physical structure of Codium beds as a structural refuge from predators and larger conspecifics (Fig. 5b).

The red alga Constantinea is a perennial with an erect thallus and a branched cylindrical stipe emerging from a small discoid holdfast that grows up to a height of approximately $15 \mathrm{~cm}$. The circular, cup-shaped blades grow through the winter each year to form an understory canopy over the benthos (Fig. 5a). While several species occur across the northwest Pacific, Constantinea rosa-marina was the only species observed in this study, occurring in both kelp forests and in isolated patches in barren grounds. While it is unknown if this alga produces chemical defenses to deter grazing, the robust structure of the stipe may be a structural defense against grazing by sea urchins. Constantinea individuals are long-lived perennials, often surviving longer than $15 \mathrm{yr}$ (Klochkova \& Pisareva 2009) and play an important ecological role by providing persistent sub-canopy habitat over the benthos, even when under intensive grazing pressure (Foreman 1977). The relationship between Constantinea and sea urchin recruits remains unclear as it is not understood if the sea urchins are associated with the plant as a food source or as a structural refuge from predation or displacement by larger conspecifics.

Another red alga positively correlated with sea urchin recruits, Schizymenia, also has an uncertain relationship with sea urchins. Schizymenia is an ephemeral alga and does not feature any robust structure that could resist grazing from or harbor sea urchin recruits. The large, thin, leafy blades often cover patches of the benthos and perhaps sea urchin recruits can find refuge beneath the dense 
cover (Fig. 5d) or use Schizymenia as a food source. However, some Schizymenia species produce compounds that have been extracted for use in antiretroviral therapy treatments in the biomedical field (Nakashima et al. 1987, Anand et al. 2016). It is unknown if these same compounds influence the palatability of Schizymenia to sea urchins.

The filamentous red alga Polysiphonia poses a puzzling relationship in that it exhibited a negative correlation in barren grounds and a positive correlation in kelp forests. Polysiphonia can occur in large, bushy tufts that sweep across the benthos, which in some ways could act as a physical deterrent to organisms that would be whipped away in the surge. The complex structure provided by the fine branching could also offer refuge for sea urchin recruits that seek shelter within the body of the plant. Polysiphonia has also been shown to induce metamorphosis in larval sea urchins and act as a refuge for post-larval juveniles (Pearce \& Scheibling 1991). In the kelp forest habitats, Polysiphonia may play this role for sea urchin recruits, whereas its role in the barren grounds differs under the higher grazing intensity. More research is needed on the relationship between sea urchin recruits and Polysiphonia from both habitats to disentangle the observed mixed result.

Pachyarthron and Corallina are branching geniculate coralline algae that create complex turf habitat over the benthos (Fig. 5f). The relationship with sea urchin recruits may be due to the physical structure of these upright corallines, which makes them more resistant to grazing. Higher biomass of these species was observed in barren grounds, where grazing intensity is likely much greater and reduces the softfleshy macroalgal cover. It is likely that the complex structure and thick, calcified cell structure make geniculate coralline algae a non-food source for small sea urchins. Pachyarthron was positively correlated with the presence of large sea urchins, which is likely a result of sea urchin grazing in the local area, removing soft-fleshy macroalgae and reducing competition for space. In this sense, the geniculate corallines were more likely to occur where large sea urchins occurred. Thus, the lack of sea urchin recruits may not be due to the corallines, but to the presence of larger conspecifics, which could displace or cannibalize the recruits (LeGault \& Hunt 2016). The variable relationship observed between sea urchin recruits and Corallina (Fig. 4) could reflect that in a sea urchin barren state, where there is little cover or refuge to be found, geniculate coralline algae can provide adequate cover for sea urchin recruits from predators. Strongylocentrotus droeba- chiensis has been shown to find refuge from predators in Corallina vancouveriensis in Washington (Yiu \& Feehan 2017); however, a strong positive relationship was not immediately obvious upon examination across the Aleutian Archipelago. Furthermore, a negative and variable relationship between the geniculate corallines and sea urchin recruits was observed, despite the expectation that geniculate corallines can chemically attract settling sea urchins (Pearce \& Scheibling 1990). Since this study reports on correlations, it would be of interest to conduct an in situ manipulative experiment with geniculate corallines in the Aleutian Archipelago, to test if patterns indeed differ from those observed in other sea urchin barren systems and account for differences between laboratory and field conditions.

\subsection{Correlations with invertebrates}

Sea urchin recruits were correlated with several phyla of benthic invertebrates, with mixed relationships, likely due to potential predator-prey interactions. The strong positive correlation between sea urchin recruits and hydrozoans in both habitats is likely indicative of sea urchins using hydroids as a refuge from other predators in the system, whether larger conspecifics, sea stars, or other macroinvertebrates (Fig. 5c). The hydroids observed in this study were erect with alternate branching, often occurring as a benthic canopy layer approximately $5 \mathrm{~cm}$ tall. Sea urchin recruits were frequently observed among the hydroids, potentially using the stinging nematocysts as a defensive fortress. Weak positive relationships of sea urchin recruits with the upright, fleshy bryozoan Alcyonidium and multiple genera of tunicates, Ascidiacea, could be due to both the biogenic structure offered by these taxa and their potential provisioning of a food source. Sea urchin recruits may be seeking refuge from other predators in the complex structure and could also be feeding on the biofilms or organisms themselves (Zhang et al. 2014).

Crabs are known to prey upon small sea urchins, and in some cases can regulate their demography and ecological role as a grazer (Steneck et al. 2013, Fagerli et al. 2014, Feehan et al. 2014). Our finding that sea urchin recruits showed strong negative correlations with Pugettia crabs fits with observations from other systems with $S$. droebachiensis in the Gulf of Maine and Norway (Steneck et al. 2013, Fagerli et al. 2014), and presents a potentially alternative pathway to demographic regulation of sea urchins in the absence of their keystone predator, the sea otter. 
However, while Pugettia were observed, and negatively correlated in barren grounds, they are unlikely to be able to control sea urchin demographics in such a sea urchin-dominated habitat, but may alter behavior (Hagen et al. 2002). The possible effect of Pugettia on sea urchin recruits is likely to be limited to kelp forests, where sea urchins occur in lower densities, the crabs in higher densities, and where the crabs are able to prey upon small, newly settled individuals (Steneck et al. 2013). Such regulation of small sea urchins by mesopredators can be critical in controlling demographics, even in the presence of sea otters, as evidenced by increases in urchins following the loss of Pycnopodia due to the recent sea star wasting epidemic in the North Pacific (Burt et al. 2018). We did observe Pycnopodia and many other sea stars during this study; however, they were often deeper than our sampling depth and did not generally occur in our surveys and, therefore, did not emerge as significantly correlated with sea urchin recruits.

Sea urchin biomass was not significantly correlated with sea urchin recruits in this study; however, density of large sea urchins was inversely correlated with density of sea urchin recruits. There is evidence that large sea urchins will displace smaller conspecifics in pursuit of food (Narvaez-Diaz 2018) and even cannibalize small sea urchins (LeGault \& Hunt 2016). It could be that the dearth of sea urchin recruits at some islands, such as Attu and Nizki/ Alaid, is due to a preponderance of large sea urchins. Large sea urchins are quite mobile and will cover meters of the sea floor per day in search of food, while small urchins may opt for a more sedentary, cryptic lifestyle (Dumont et al. 2004). These ontogenetic shifts in behavior lead to differences in growth, where small sea urchins express slower growth than large urchins due to fewer opportunities to feed on high quality food (Himmelman 1986). The relationship between larger sea urchins and new recruits may also be based on larval supply. Some islands, and even some sites within islands, may differ in the supply of larval sea urchins. While larval supply has not been examined at these islands/sites, it should be noted that for this study, some barren and kelp sites within an island were only tens of meters apart, so larval supply was probably similar.

In the central and western Aleutians, sea urchin recruitment is influenced by patterns of sea urchin size structure, probably in combination with the associated biological community. The findings of this study have revealed that specific species correlate with sea urchin recruitment, which was manifested in both alternate stable states, barren grounds and kelp forests. To our knowledge, this is the first paper to demonstrate this potential relationship. While patterns of community structure are obviously different between habitats, our findings suggest that within habitat differences in community structure, specifically the preponderance of the specific taxa identified in this study, could influence the ability for temperate reef systems to flip between alternate stable states by shaping patterns of sea urchin recruitment.

Acknowledgements. We appreciate the support of Matthew Edwards of San Diego State University for his support and collaboration in this study while aboard the R/V 'Oceanus' as part of the National Science Foundation funded study (OCE1435194). We acknowledge the field efforts made by Jacob Metzger, Alex Ravelo, Aaron Bland, Melissa Good, Sarah Traiger, and other graduate students in the Konar/ Iken Lab at UAF to collect and process the multitude of samples and provide feedback on early versions of the manuscript. We also thank Scott Gabara and the Edwards lab graduate students for their field support and feedback. Any use of trade, firm, or product names is for descriptive purposes only and does not imply endorsement by the US Government.

\section{LITERATURE CITED}

Anand N, Rachel D, Thangaraju N, Anantharaman P (2016) Potential of marine algae (sea weeds) as source of medicinally important compounds. Plant Genet Resour 14: 303-313

Anderson MJ, Gorley RN, Clarke KR (2008) PERMANOVA+ for PRIMER: Guide to software and statistical methods. PRIMER-e, Plymouth

*Bady SM, Scheibling RE (2006) Changes in growth and reproduction of green sea urchins, Strongylocentrotus droebachiensis (Müller), during repopulation of the shallow subtidal zone after mass mortality. J Exp Mar Biol Ecol 335:277-291

* Burt JM, Tinker MT, Okamoto DK, Demes KW, Holmes K, Salomon AK (2018) Sudden collapse of a mesopredator reveals its complementary role in mediating rocky reef regime shifts. Proc R Soc B 285:20180553

Clarke KR, Gorley RN (2015) Getting started with PRIMER v7. PRIMER-e, Plymouth

Clarke KR, Gorley RN, Somerfield PJ, Warwick RM (2014) Change in marine communities: an approach to statistical analysis and interpretation. PRIMER-e, Plymouth

* Dumont CP, Himmelman JH, Russell MP (2004) Size-specific movement of green sea urchins Strongylocentrotus droebachiensis on urchin barrens in eastern Canada. Mar Ecol Prog Ser 276:93-101

* Dumont CP, Himmelman JH, Russell MP (2006) Daily movement of the sea urchin Strongylocentrotus droebachiensis in different subtidal habitats in eastern Canada. Mar Ecol Prog Ser 317:87-99

Ebert TA (2010) Demographic patterns of the purple sea urchin Strongylocentrotus purpuratus along a latitudinal gradient, 1985-1987. Mar Ecol Prog Ser 406:105-120

Edwards M, Konar B (2018a) Epibenthic community abun- 
dance in Aleutian Island kelp forests, June 2016 and July 2017 (Kelp Forest Ecosystem Engineer Loss project). Biological and Chemical Oceanography Data Management Office (BCO-DMO). Dataset version 2018-02-20. doi:10. 1575/1912/bco-dmo.727180.1

Edwards M, Konar B (2018b) Epibenthic community biomass in Aleutian Island kelp forests, June 2016 and July 2017 (Kelp Forest Ecosystem Engineer Loss project). Biological and Chemical Oceanography Data Management Office (BCO-DMO). Dataset version 2018-02-20. doi:10. 1575/1912/bco-dmo.728084.1

Estes JA, Duggins DO (1995) Sea otters and kelp forests in Alaska: generality and variation in a community ecological paradigm. Ecol Monogr 65:75-100

Estes JA, Tinker MT, Williams TM, Doak DF (1998) Killer whale predation on sea otters linking oceanic and nearshore ecosystems. Science 282:473-476

Fagerli CW, Norderhaug KM, Christie H, Pedersen MF, Fredriksen S (2014) Predators of the destructive sea urchin Strongylocentrotus droebachiensis on the Norwegian coast. Mar Ecol Prog Ser 502:207-218

Feehan CJ, Francis FTY, Scheibling RE (2014) Harbouring the enemy: kelp holdfasts protect juvenile sea urchins from predatory crabs. Mar Ecol Prog Ser 514:149-161

Filbee-Dexter K, Scheibling RE (2014) Sea urchin barrens as alternative stable states of collapsed kelp ecosystems. Mar Ecol Prog Ser 495:1-25

Foreman RE (1977) Benthic community modification and recovery following intensive grazing by Strongylocentrotus droebachiensis. Helgol Wiss Meeresunters 30: 468-484

* Gagnon P, Himmelman JH, Johnson LE (2004) Temporal variation in community interfaces: kelp-bed boundary dynamics adjacent to persistent urchin barrens. Mar Biol 144:1191-1203

Hagen NT, Andersen Å, Stabell O (2002) Alarm responses of the green sea urchin, Strongylocentrotus droebachiensis, induced by chemically labelled durophagous predators and simulated acts of predation. Mar Biol 140:365-374

*Himmelman JH (1986) Population biology of green sea urchins on rocky barrens. Mar Ecol Prog Ser 33: 295-306

Johnson CR, Banks SC, Barrett NS, Cazassus F and others (2011) Climate change cascades: shifts in oceanography, species' ranges and subtidal marine community dynamics in eastern Tasmania. J Exp Mar Biol Ecol 400:17-32

Klochkova NG, Pisareva NA (2009) The genus Constantinea (Rhodophyta: Gigartinales) in the far-eastern seas of Russia. Russ J Mar Biol 35:206-214

Konar B, Edwards MS, Estes JA (2014) Biological interactions maintain the boundaries between kelp forests and urchin barrens in the Aleutian Archipelago. Hydrobiologia 724:91-107

Krumhansl KA, Okamoto DK, Rassweiler A, Novak M and others (2016) Global patterns of kelp forest change over the past half-century. Proc Natl Acad Sci USA 113: 13785-13790

KLarson SE, Bodkin JL, VanBlaricom GR (eds) (2015) Sea otter conservation. Academic Press, Elsevier

* LeGault KN, Hunt HL (2016) Cannibalism among green sea urchins Strongylocentrotus droebachiensis in the laboratory and field. Mar Ecol Prog Ser 542:1-12

KLing SD, Scheibling RE, Rassweiler A, Johnson CRR and others (2015) Global regime shift dynamics of cata- strophic sea urchin overgrazing. Philos Trans R Soc B 370:20130269

Ling SD, Kriegisch N, Woolley B, Reeves SE (2019) Densitydependent feedbacks, hysteresis, and demography of overgrazing sea urchins. Ecology 100:e02577

Lyons DA, Scheibling RE, Van Alstyne KL (2010) Spatial and temporal variation in DMSP content in the invasive seaweed Codium fragile ssp. fragile: effects of temperature, light and grazing. Mar Ecol Prog Ser 417: 51-61

McArdle BH, Anderson MJ (2001) Fitting multivariate models to community data: a comment on distance-based redundancy analysis. Ecology 82:290-297

* Metzger JR, Konar B, Edwards MS (2019) Assessing a macroalgal foundation species: community variation with shifting algal assemblages. Mar Biol 166:156

* Nakashima H, Kido Y, Kobayashi N, Motoki Y, Neushul M, Yamamoto N (1987) Antiretroviral activity in a marine red alga: reverse transcriptase inhibition by an aqueous extract of Schizymenia pacifica. J Cancer Res Clin Oncol 113:413-416

Narvaez-Diaz C (2018) Green urchin demography in a subarctic ecosystem: patterns and processes. PhD dissertation, Université Laval, Quebec

* Pearce CM, Scheibling RE (1990) Induction of metamorphosis of larvae of the green sea urchin, Strongylocentrotus droebachiensis, by coralline red algae. Biol Bull 179: 304-311

* Pearce CM, Scheibling RE (1991) Effect of macroalgae, microbial films, and conspecifics on the induction of metamorphosis of the green sea urchin Strongylocentrotus droebachiensis (Müller). J Exp Mar Biol Ecol 147: 147-162

*Pederson HG, Johnson CR (2006) Predation of the sea urchin Heliocidaris erythrogramma by rock lobsters (Jasus edwardsii) in no-take marine reserves. J Exp Mar Biol Ecol 336:120-134

* Rasher DB, Steneck RS, Estes JA, Halfar J and others (2020) Trophic cascades, climate change, and the fate of a subarctic reef: climate change amplifies trophic cascades in a kelp forest ecosystem. Science 369:1351-1354

Rowley RJ (1989) Settlement and recruitment of sea urchins (Strongylocentrotus spp.) in a sea-urchin barren ground and a kelp bed: are populations regulated by settlement or post-settlement processes? Mar Biol 100:485-494

Scheibling RE, Hatcher BG (2013) Strongylocentrotus droebachiensis. In: Lawrence JM (ed) Sea urchins: biology and ecology, 3rd edn. Academic Press, San Diego, CA, p 381-412

Sheppard-Brennand H, Dworjanyn SA, Poore AG (2017) Global patterns in the effects of predator declines on sea urchins. Ecography 40:1029-1039

* Steneck RS, Leland A, McNaught DC, Vavrinec J (2013) Ecosystem flips, locks, and feedbacks: the lasting effects of fisheries on Maine's kelp forest ecosystem. Bull Mar Sci 89:31-55

* Steneck RS, David R, Hay ME (2017) Herbivory in the marine realm. Curr Biol 27:R484-R489

Suskiewicz TS, Johnson LE (2017) Consumption rates of a key marine herbivore: a review of the extrinsic and intrinsic control of feeding in the green sea urchin. Mar Biol 164:131

* Trowbridge CD (1995) Establishment of the green alga Codium fragile ssp. tomentosoides on New Zealand 
rocky shores: current distribution and invertebrate grazers. J Ecol 83:949

Van Alstyne KL, Puglisi MP (2007) DMSP in marine macroalgae and macroinvertebrates: distribution, function, and ecological impacts. Aquat Sci 69:394-402

Van Alstyne KL, Wolfe GV, Freidenburg TL, Neill A, Hicken C (2001) Activated defense systems in marine macroalgae: evidence for an ecological role for DMSP cleavage. Mar Ecol Prog Ser 213:53-65

Watt J, Siniff DB, Estes JA (2000) Inter-decadal patterns of

Editorial responsibility: Jean-Sébastien Lauzon-Guay, Dartmouth, Nova Scotia, Canada

Reviewed by: 3 anonymous referees population and dietary change in sea otters at Amchitka Island, Alaska. Oecologia 124:289-298

* Yiu DS, Feehan CJ (2017) Articulated coralline algae provide a spatial refuge to juvenile sea urchins from predatory crabs. Mar Biol 164:76

Zhang W, Chang Y, Luo S, Zhou H, Tian X, Ding J, Chen X (2014) Effects of biofilms as the main and as a supplementary food on the survival, somatic growth and gonad enhancement of sea urchin Strongylocentrotus intermedius. Aquacult Int 22:925-936

Submitted: March 12, 2020

Accepted: December 21, 2020

Proofs received from author(s): March 19, 2021 